\title{
Characterization, Antimicrobial Properties and Coatings Application of Gellan Gum Oxidized with Hydrogen Peroxide
}

\author{
Yushuang Lu, Xiaojian Zhao and Sheng Fang * (i) \\ School of Food Science and Biotechnology, Zhejiang Gongshang University, Xuezheng Street No. 18, \\ Hangzhou 310018, China; lyszjgsl@163.com (Y.L.); zhaoxj0822@foxmail.com (X.Z.) \\ * Correspondence: fszjgsu@163.com; Tel.: +86-1309-375-2831; Fax: +86-571-2800-8900
}

Received: 19 December 2018; Accepted: 14 January 2019; Published: 17 January 2019

\begin{abstract}
The effect of hydrogen peroxide $\left(\mathrm{H}_{2} \mathrm{O}_{2}\right)$ oxidation on the physicochemical, gelation and antimicrobial properties of gellan gum was studied. The oxidized gellan gum (OGG) was characterized by measuring the carboxyl/carbonyl group contents, Fourier transform infrared spectroscopy (FTIR) and proton nuclear magnetic resonance $\left({ }^{1} \mathrm{H}-\mathrm{NMR}\right)$ spectroscopy. The $\mathrm{H}_{2} \mathrm{O}_{2}$ oxidation resulted in a large increase in the carboxyl groups in gellan gum. The OGG lost gelation ability by oxidation even in the presence of metal ions. The antimicrobial activities of the OGG against Gram-positive bacteria (Staphylococcus aureus), Gram-negative bacteria (Escherichia coli), and fungal (Aspergillus niger) were tested. The OGG could inhibit the growth of both bacteria and fungal, and the activity was improved with an increase in the oxidation level. Finally, the application of the OGG as an active coatings material to extend the storage of apples was tested.
\end{abstract}

Keywords: oxidation; gellan gum; spectroscopy; gelation; antimicrobial

\section{Introduction}

Microbial exopolysaccharides can be produced on a very large scale and with potential applications in many areas as renewable non-petrochemical-based materials. Application areas of exopolysaccharides are widening, ranging between foods, cosmetics, biomedical and daily-life products [1-3]. The chemical modifications of microbial exopolysaccharides can introduce hydrophobic, acidic, basic, or other desired functional groups into structures by esterification, etherification, sulfurization, amidation, and oxidation et al. which greatly extends their applications $[4,5]$.

Gellan gum, as a commercially important Sphingomonas elodea exopolysaccharide, is a linear anionic polymer with tetrasaccharide repeats including one glucuronic acid, one rhamnose, and two glucose carbohydrates [6,7]. It has been well used in food, cosmetics, and bioengineering due to its acid and heat resistance, and good processing ability [7,8]. The physicochemical modification of gellan gum facilitated their applications in different areas. For example, gellan gum was carboxymethylated by reacting with monochloroacetic acid which gave them higher mucoadhesive strength [9]. Matricardi et al. [10] prepared a crosslinked gellan gum and showed good control release properties for drugs. A recent review [8] has reviewed the functionalization strategies of the gellan gum for biomedical applications.

Oxidation has been widely used for the functionalization of gellan gums [8]. Redouan et al. [11] selectively oxidized the gellan gum by using sodium hypochlorite in the presence of 2,2,6,6tetramethylpiperidine-1-oxyl radical (TEMPO) and $\mathrm{NaBr}$ in aqueous solution. They obtained a water-soluble natural polymer which might find applications in medical and pharmaceutical areas. Gong et al. [12] developed a hydrogel-based scaffolding system by oxidative cleavage on the gellan 
gum backbones with $\mathrm{NaIO}_{4}$ while providing a promising platform for cartilaginous regeneration. Tang et al. [13] used $\mathrm{NaIO}_{4}$ to oxidize the adjacent hydroxyl groups in the gellan gum, which resulted in gels with low gelation temperature and improved cell compatibility. Oxidant agents such as TEMPO, $\mathrm{NaBr} / \mathrm{NaOCl}, \mathrm{N}_{2} \mathrm{O}_{4}$, and $\mathrm{H}_{2} \mathrm{O}_{2}$ are always selected for the chemical modification of polysaccharides [14,15]. $\mathrm{H}_{2} \mathrm{O}_{2}$ has strong oxidizing properties and only releases water as a by-product [15]. $\mathrm{H}_{2} \mathrm{O}_{2}$ can oxidize the primary alcohol group to an aldehyde group, or further to a carboxyl group. The process can effectively introduce carboxyl and/or carbonyl groups into the treated polysaccharides [15]. The oxidation of the gellan gum by $\mathrm{H}_{2} \mathrm{O}_{2}$ has not been studied. More data about the effects of $\mathrm{H}_{2} \mathrm{O}_{2}$ oxidation on the physicochemical and functional properties of the gellan gum is essential for extending its applications.

This study used $\mathrm{H}_{2} \mathrm{O}_{2}$ as a green oxidant to oxidize the gellan gum with copper sulfate as a catalyst. The structure and properties of the oxidized gellan gum (OGG) were characterized by determining the carbonyl/carboxyl content using Fourier transform infrared spectroscopy (FTIR) and the proton nuclear magnetic resonance $\left({ }^{1} \mathrm{H}-\mathrm{NMR}\right)$ spectrum. The gel properties of the OGGs were tested. In addition, the antimicrobial activities of the OGG against Gram-positive bacteria (Staphylococcus aureus), Gram-negative bacteria (Escherichia coli) and fungal (Aspergillus niger) were studied. To the best of our knowledge, the antibacterial activity of the OGG had not been tested. Finally, as an application, the OGG was tested as an antibacterial film material on food surfaces in the extending of shelf life.

\section{Materials and Methods}

\subsection{Materials}

The low acyl gellan gum was supplied by CP Kelco (San Diego, CA, USA). The low acyl gellan gum was checked by FTIR and ${ }^{1} \mathrm{H}-\mathrm{NMR}$ for structure, and gel permeation chromatography (GPC) for molecular weight. The $\mathrm{H}_{2} \mathrm{O}_{2}$ (30\% in aqueous) was purchased from Sinopharm Chemical Reagent Co., Ltd. (Shanghai, China). Escherichia coli (E. coli, CGMCC1.8745), Staphylococcus aureus (S. aureus, CGMCC 1.1861) and Aspergillus niger (A. niger CGMCC3.3928) were obtained from China General Microbiological Culture Collection Center (CGMCC, Beijing, China).

\subsection{Preparation of Oxidized Gellan Gum}

The OGG was prepared following the method of oxidized amyloses reported by Ying et al [16]. Briefly, $2 \mathrm{~g}$ of gellan gum was dissolved in $70 \mathrm{~mL}$ of deionized water at $90{ }^{\circ} \mathrm{C}$. After the solution cooled to $50{ }^{\circ} \mathrm{C}, 4 \mathrm{~mL}$ of $0.05 \% \mathrm{CuSO}_{4}$ solution was added, $30 \% \mathrm{H}_{2} \mathrm{O}_{2}$ was then added at different dosages $(10,20,30$ and $40 \mathrm{~mL})$ with stirring. The solution was allowed to react for $5 \mathrm{~h}$. After the reaction, the mixture was dialyzed to remove $\mathrm{Cu}^{2+}$ and $\mathrm{H}_{2} \mathrm{O}_{2}$ before freeze drying. The process was checked by determining the conductivity of the dialysate. The oxidized gellan gums were denoted as OGG-1, OGG-2, OGG-3 and OGG-4 when the dosages of $\mathrm{H}_{2} \mathrm{O}_{2}$ were 10, 20, 30 and $40 \mathrm{~mL}$, respectively.

\subsection{Carboxyl Content Determination}

The carboxyl content was determined according to the calcium-acetate method [17]. The samples were kept in a vacuum oven at $60^{\circ} \mathrm{C}$ for $48 \mathrm{~h} .45 \mathrm{mg}$ of selected OGG was dissolved in $30 \mathrm{~mL}$ water. Then $10 \mathrm{~mL}$ of $0.1 \mathrm{M}$ calcium acetate was added. The mixture was stirred for $1 \mathrm{~h}$ to promote the reaction. Then, the liquid was titrated using $0.01 \mathrm{M} \mathrm{NaOH}$. A blank determination with gellan gum was performed in the same manner. The carboxyl content was calculated as follows:

$$
\operatorname{COOH}(\%)=\frac{\left[V_{\mathrm{NaOH}}-V_{0}\right] \times 0.01 \times 45 \times 100}{m}
$$


where $V_{\mathrm{NaOH}}$ and $V_{0}$ was the volume of $\mathrm{NaOH}$ solution in titration for the OGG and control sample, respectively; $m$ was the weight $(\mathrm{g})$ of the OGG sample, and 45 was the molecular weight of the carboxyl group.

\subsection{Carbonyl Content Determination}

The OGGs were converted to oxime by Schiff's base reaction with hydroxylamine hydrochloride. The calibration curve was determined at first. Briefly, in different volumes $(0.5,1.0,1.5,2.0,2.5$, and $3.0 \mathrm{~mL})$ of $4.22 \times 10^{-4} \mathrm{M}$ glyoxal solution, $1 \mathrm{~mL}$ of $1.5 \%(\mathrm{w} / \mathrm{w})$ sodium acetate and $1 \mathrm{~mL}$ of $0.2 \%(\mathrm{w} / \mathrm{w})$ hydroxylamine hydrochloride were added. The reaction was carried out at $50{ }^{\circ} \mathrm{C}$ for $20 \mathrm{~min}$. Then the solution was diluted to $50 \mathrm{~mL}$ and measured at $233 \mathrm{~nm}$ using a UV-2600 spectrophotometer (Shimadzu, Kyoto, Japan). The calibration curve between the absorbance and carbonyl content was calculated as $y=9488.8 x+0.0085$ ( $x$ is the carbonyl content, $y$ is the UV absorbance). The OGG sample (10 mg) was dissolved in deionized water and measured. The carbonyl content of the OGGs was calculated as:

$$
\mathrm{CO}(\%)=\frac{(y-0.0085) \times 0.05 \times 28 \times 100}{9488.8 \times m}
$$

where $m$ was the weight $(\mathrm{g})$ of the sample and 28 was the molecular weight of the carbonyl group. Each set of tests was done in triplicate, and the average values were selected.

\subsection{Fourier Transform Infrared Spectroscopy (FTIR)}

The FTIR spectra of the OGGs were obtained from a Fourier Transform Infrared Spectrometer (Nicolet is5, Thermo Scientific, Waltham, MA, USA). The samples were kept in a vacuum oven at $60^{\circ} \mathrm{C}$ for $48 \mathrm{~h} .1 \mathrm{mg}$ of sample and $100 \mathrm{mg}$ of $\mathrm{KBr}$ were mixed, ground, compressed and then tested. The range of wavenumbers was from $4000 \mathrm{~cm}^{-1}$ to $400 \mathrm{~cm}^{-1}$ with the resolution of $4 \mathrm{~cm}^{-1}$.

\subsection{Proton Nuclear Magnetic Resonance ( $\left.{ }^{1} H-N M R\right)$ Spectroscopy}

The proton nuclear magnetic resonance $\left({ }^{1} \mathrm{H}-\mathrm{NMR}\right)$ spectra of the OGGs were collected at $308 \mathrm{~K}$ by a Bruker Avance III $600 \mathrm{MHz}$ NMR Spectrometer (Billerica, MA, USA). The unoxidized low acyl gellan gum needs to be dissolved at high temperatures, so the H-NMR spectra of the low acyl gellan gum was performed by an Avance III $400 \mathrm{MHz}$ NMR Spectrometer (Billerica, MA, USA) at $353 \mathrm{~K}$. The samples were dissolved in $\mathrm{D}_{2} \mathrm{O}$ at about $20 \mathrm{mg} / \mathrm{mL}$.

\subsection{Gel Properties of the Oxidized Gellan Gum in the Presence of Ions}

The OGG powder was dispersed in $100 \mathrm{~mL}$ deionized water at room temperature. It was then placed in a $90{ }^{\circ} \mathrm{C}$ water bath and stirring was undertaken until the powder was completely dissolved to form a transparent, clear solution. Then, $0.06 \%$ of $\mathrm{CaCl}_{2}$ or $1.7 \%$ of $\mathrm{NaCl}$ were added to the solution and stirred well until completely dissolved. Finally, it was left to cool naturally and its gel formation was observed.

\subsection{Antibacterial Activity of the Oxidized Gellan Gum}

Two food-related bacterial strains E. coli and S. aureus were selected to evaluate the antibacterial property of the OGGs. The strain was inoculated in nutrient broth (NB), and then incubated at $37^{\circ} \mathrm{C}$ for $12 \mathrm{~h}$. The stationary phase was determined by optical density at $600 \mathrm{~nm}$. A working solution was prepared by diluting the above subculture into PBS, with the final bacterial concentration of $10^{6} \mathrm{CFU}$ (colony forming unit) $/ \mathrm{mL}$. The number of bacteria was measured by the plate counting method, which was performed three times to obtain representative CFU values.

The minimum inhibitory concentration (MIC) was measured using a broth dilution method for bacteria. $1 \mathrm{~mL}$ of NB broth with various contents of the OGG was placed into a 24-well plate. Then $20 \mu \mathrm{L}$ of bacterial suspension was added to each well and incubated for $24 \mathrm{~h}$ with constant shaking 
at $150 \mathrm{rpm}$ and $37^{\circ} \mathrm{C}$. The minimum concentration of the sample at which microbial growth was measurably inhibited was taken as the MIC.

\subsection{Antifungal Activity of the Oxidized Gellan Gum}

The antifungal activity of the OGG was measured by evaluating the ability to control $A$. niger growth according to Reference [18]. $1 \mathrm{~mL}$ of potato dextrose broth (PDB) containing various contents of the OGG was placed into each well of a 24-well plate. Then $100 \mu \mathrm{L}$ of $A$. niger suspension was added to each well. The culture medium was incubated at $28^{\circ} \mathrm{C}$ for $24 \mathrm{~h}$. After that, $100 \mu \mathrm{L}$ of culture medium was collected and reincubated on potato dextrose agar (PDA) plates at $28^{\circ} \mathrm{C}$ for 2 days. The appearances of $A$. niger colonies on PDA plates were observed to evaluate the antifungal activity of the OGG.

\subsection{Effect of the Oxidized Gellan Gum on Apple Preservation}

Apples were selected with similar maturity, size, and shape. Then washed and disinfected in sodium hypochlorite with a concentration of $0.05 \%(\mathrm{v} / \mathrm{v})$. Cut the same incision on each apple surface and apply the prepared coating-forming solution separately. Three groups of coating-forming solution were prepared: (A) $5 \mathrm{mg} / \mathrm{mL}$ guar gum and $10 \mathrm{mg} / \mathrm{mL}$ glycerol; (B) $5 \mathrm{mg} / \mathrm{mL}$ guar gum, $10 \mathrm{mg} / \mathrm{mL}$ glycerol and $10 \mathrm{mg} / \mathrm{mL}$ OGG-4; (C) $5 \mathrm{mg} / \mathrm{mL}$ guar gum, $10 \mathrm{mg} / \mathrm{mL}$ glycerol and $20 \mathrm{mg} / \mathrm{mL}$ OGG-4. The appearance of the apple was recorded at different times by taking photos.

\section{Results and Discussions}

\subsection{Characterizations}

\subsubsection{Carboxyl and Carbonyl Contents of the Oxidized Gellan Gums}

Table 1 showed the carboxyl and carbonyl contents of different OGGs. It showed that the increase in the $\mathrm{H}_{2} \mathrm{O}_{2}$ amount resulted in a corresponding increase in the carbonyl and carboxyl contents. The carbonyl content increased from $0.36 \%$ to $0.87 \%$, while the carboxyl content increased from $6.11 \%$ to $14.51 \%$ and the $\mathrm{H}_{2} \mathrm{O}_{2}$ increased from 10 to $40 \mathrm{~mL}$. The carbonyl content is much less than the carboxyl content. The same behavior in oat $\beta$-glucan was observed by Moura et al. [19], that the carbonyl and carboxyl contents increased with increasing $\mathrm{H}_{2} \mathrm{O}_{2}$ level and reaction time. These results suggest that the OGG with different oxidation levels are successfully prepared and the carbonyl and carboxyl content can be adjusted.

Table 1. Carboxyl content and carbonyl content of oxidized gellan gum.

\begin{tabular}{ccc}
\hline Sample & Carboxyl Content (\%) & Carbonyl Content (\%) \\
\hline PGG & - & - \\
OGG-1 & $6.11 \pm 0.05$ & $0.36 \pm 0.01$ \\
OGG-2 & $7.96 \pm 0.04$ & $0.44 \pm 0.03$ \\
OGG-3 & $11.82 \pm 0.01$ & $0.75 \pm 0.04$ \\
OGG-4 & $14.51 \pm 0.03$ & $0.87 \pm 0.02$ \\
\hline
\end{tabular}

\subsubsection{Fourier Transform Infrared Spectroscopy Analysis}

Figure 1 shows that the pure gellan gum (PGG) and all the OGGs present characteristic peaks at around 2929, 1620 and $1069 \mathrm{~cm}^{-1}$. The band corresponding to $\mathrm{C}-\mathrm{H}$ vibrations of sugar occurs at approximately $2929 \mathrm{~cm}^{-1}$. The strong band at around $1069 \mathrm{~cm}^{-1}$ was attributed to the C-O-C stretching. The result showed that all the OGGs had a new characteristic peak around $1731 \mathrm{~cm}^{-1}$. The peaks became more significant with the increase of oxidation degree. Similar results reported that new absorption peaks around $1730 \mathrm{~cm}^{-1}$ were detected in the oxidized konjac glucomannan by 
$\mathrm{H}_{2} \mathrm{O}_{2}$ [20]. It is known that esters, aldehydes, and carboxylic acids will have $\mathrm{C}=\mathrm{O}$ stretching peaks around $1715 \mathrm{~cm}^{-1}$. The carboxylic group exhibits a peak around $1730 \mathrm{~cm}^{-1}$ in the dissociated form, and $1620 \mathrm{~cm}^{-1}$ in the salt form [21]. So, the increasing of band peak around $1731 \mathrm{~cm}^{-1}$ indicates the formation of carboxylic groups in the OGGs which is in accordance with the findings in Table 1. Similar results were observed in oxidized amylose and oxidized cellulose when the hydroxyl groups were transformed to carbonyl and carboxyl groups [22]. These results showed that the carboxyl groups had been successfully introduced into the structure of gellan gum by $\mathrm{H}_{2} \mathrm{O}_{2}$ oxidation and supported the proposed oxidation mechanisms.

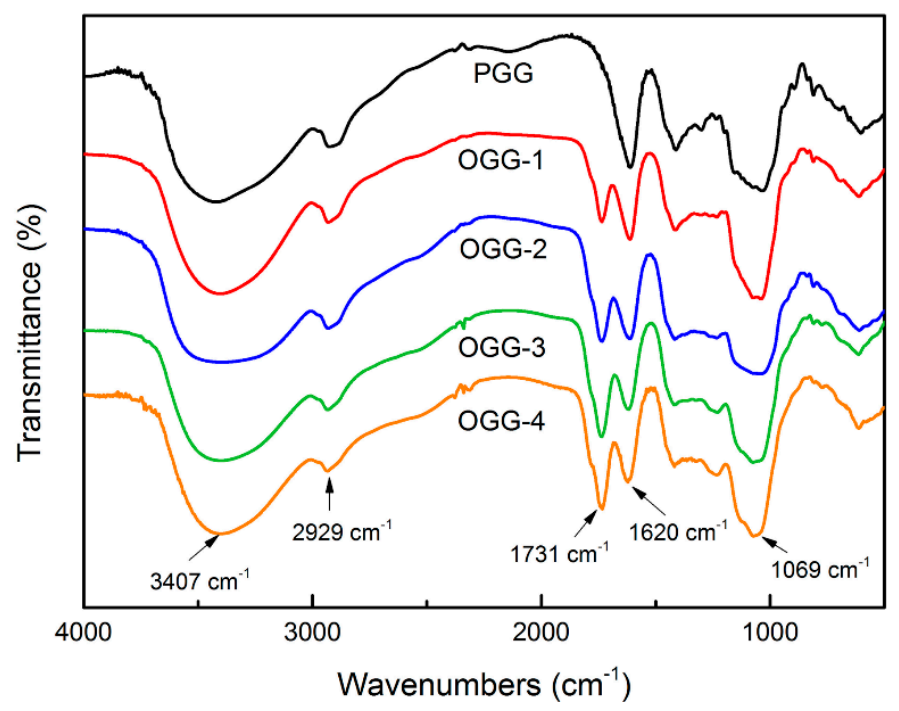

Figure 1. FTIR (Fourier transform infrared spectroscopy) spectra of pure gellan gum (PGG) and oxidized gellan gum (OGG) with different degrees of oxidation.

\subsubsection{Nuclear Magnetic Resonance Spectrum}

The ${ }^{1} \mathrm{H}-\mathrm{NMR}$ of the low acyl gellan gum, OGG-1 and OGG-3 were tested and compared. Samples 1 and 3 have been demonstrated with different oxidation levels. The ${ }^{1} \mathrm{H}-\mathrm{NMR}$ spectrum is shown in Figure 2. The obtained spectra of gellan gum showed characteristic peaks corresponding to $-\mathrm{CH}_{3}$ of rhamnose ( $\delta 1.20-1.4 \mathrm{ppm})$, - $\mathrm{CH}$ - of glucose, glucuronic acid, and rhamnose $(\delta 3.8-4.9 \mathrm{ppm})$, and -CHof glycosidic bonds in sugars $(\delta 5.0-5.6 \mathrm{ppm})$. The peaks at 5.6, 5.4 and $5.1 \mathrm{ppm}$ were assigned to the $\mathrm{H}$ of $\mathrm{C} 1$ with glucoside bonds of the rhamnose, glucuronic acid, and glucose, respectively [23]. Because there is a dissolving problem of gellan gum in cold water, the NMR spectrum of gellan gum was tested at $80^{\circ} \mathrm{C}$. The chemical shifts of OGG-1 and OGG-3 shifted to lower $\delta$ values at a low temperature.

It was seen that the original single peak of $-\mathrm{CH}_{3}$ on the rhamnose structure (around $\delta 1.2$ for the OGGs) split into the multiple peaks in the OGGs. Peaks corresponding to the - $\mathrm{CH}$ - of glycosidic bonds, especially at $\delta$ value of 5.1 (corresponding to the glycosidic bond of rhamnose in the OGGs), became smaller than these in the pure gellan gum. Moreover, these changes became more obvious as the oxidation level increased. The oxidation of the glucoside bond in the rhamnose unit made the proton environments of the $-\mathrm{CH}_{3}$ group become different which led to the split of the original peaks. These results demonstrated that the partial cleavage of the glucosidic linkages occured in the oxidation process of the gellan gum by $\mathrm{H}_{2} \mathrm{O}_{2}$. Some small and new peaks appeared in the 2.0-2.3 ppm and 6.5-7.5 ppm regions, which did not belong to the normal sugar structures [23]. It is interesting to find that small peaks in these regions could also be found in the H-NMR spectrum of oxidized gellan gum using $\mathrm{NaIO}_{4}$ as oxidizing agents by Gong et al. [12]. We supposed that some acetylate or ester groups were introduced from the oxidation process [24]. However, it was hard to explain these molecular structures. It was also strange that no peaks, even small, were found at the region larger than $8.05 \mathrm{ppm}$ which belonged to the terminal aldehyde group [12]. It suggested that there may not be any 
terminal aldehyde groups in the OGGs obtained via Fenton-type oxidation, and the carbonyl contents determined may belong to the ketone or carboxyl groups. The results were in accordance with the FTIR results that carboxyl groups are favorably formed in the Fenton-type oxidation of polysaccharides.

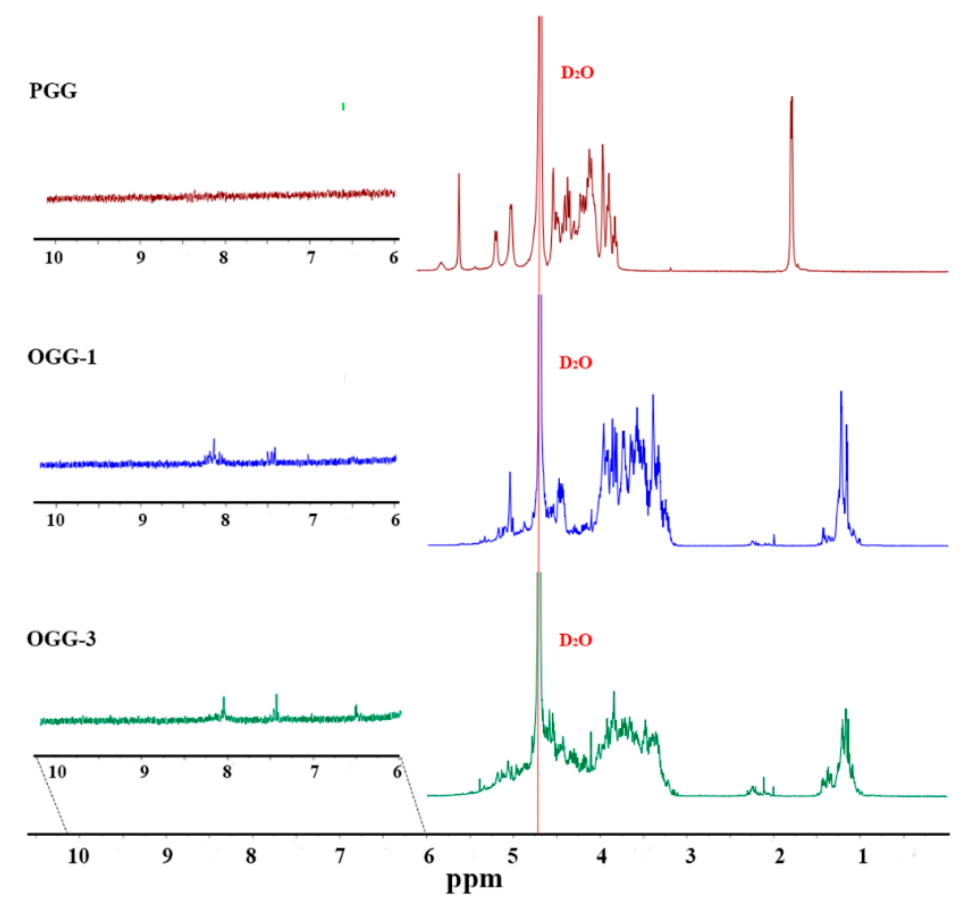

Figure 2. The ${ }^{1} \mathrm{H}-\mathrm{NMR}$ spectra of gellan gum (PGG) and oxidized gellan gum (OGG-1 and OGG-3).

\subsection{Oxidation Mechanisms}

Many studies have used $\mathrm{H}_{2} \mathrm{O}_{2}$ as an oxidant and copper sulfate as a catalyst to oxidize polysaccharides with a mechanism belonging to the scope of Fenton chemistry. $[16-18,25]$ In the presence of a metal catalyst, the mechanisms of polysaccharides oxidation by $\mathrm{H}_{2} \mathrm{O}_{2}$ are very complex [26,27]. According to the Fenton reaction, $\mathrm{H}_{2} \mathrm{O}_{2}$ decomposes rapidly and forms hydroxyl radicals in the presence of transition metal. These hydroxyl radicals are very powerful oxidizing species which can oxidize polysaccharides rapidly. The low acyl gellan gum structure consists of monosaccharides $\beta$-D-glucose, $\alpha$-L-rhamnose and $\beta$-D-glucuronic acid in molar ratios of 2:1:1 linked together by glycosidic bonds. According to references, we supposed that there might be two possible oxidative pathways as shown in Figure 3.

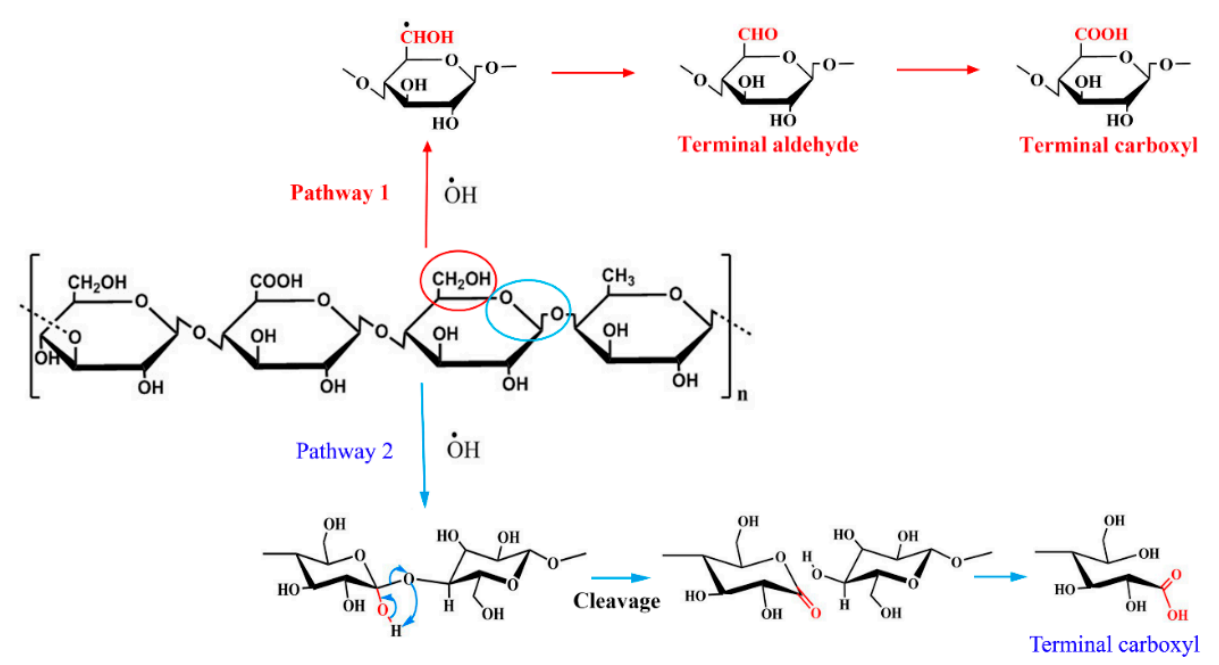

Figure 3. Pathways for gellan gum oxidation in $\mathrm{H}_{2} \mathrm{O}_{2}$ in the presence of ions. 
Pathway 1 is proposed via the oxidation of hydroxyl groups such as C6 hydroxyl to carbonyl groups and then to carboxyl groups [26]. As shown in Table 1, the major functional group produced was carboxyl which progressively increased with the $\mathrm{H}_{2} \mathrm{O}_{2}$ amount while only little carbonyl groups were formed. The results agreed with earlier studies that the oxidation of polysaccharides favors the formation of carboxyl groups $[16,17,28]$. It was suggested that once the carbonyl groups were formed, they would be rapidly converted to carboxyl groups [28]. Therefore, only a small amount of carbonyl groups were accumulated as shown in this study. Parallel reaction paths in which carboxyl groups are formed by the oxidation of glycoside bonds as shown in pathway 2 were also reported [29]. As shown in the figure, the attacking of the $\mathrm{C} 1$ position in sugar by hydroxyl radicals leads to the cleavage of glycoside bonds of polysaccharides and forms acidic functionality groups. Recently, this pathway was reported as the main molecular mechanism of polysaccharide oxidative cleavage via a Fenton-type reaction in the presence of a copper enzyme [30]. This oxidative cleavage would lead to varied small linear polysaccharides with functional carboxyl groups such as a glucuronic acid group. It is suggested that pathway 2 is dominated in the oxidation process.

\subsection{Gelation Properties}

\section{Gelling Properties of the Oxidized Gellan Gums}

The low acyl gellan gum has a property to form a gel in the presence of metal ions such as $\mathrm{Na}^{+}$and $\mathrm{Ca}^{2+}$. Therefore, the gel formation properties of the OGGs were tested with the addition of ions as shown in Figure 4. However, all the OGGs could no longer form a gel even with the quite high concentration (up to 1.2\%, Figure 5). The gelation of gellan gum is considered as the formation of double-helical junction zones which is associated and stabilized by cations and water molecules [31]. The oxidation of hydroxyl groups and the cleavage of glycoside bonds may strongly break the intramolecular hydrogen bonds, which leads to poor gelation stability.

A

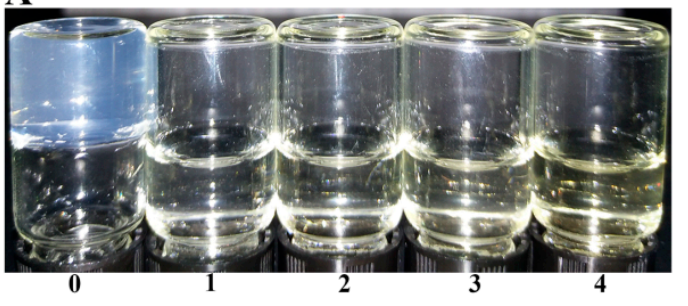

B

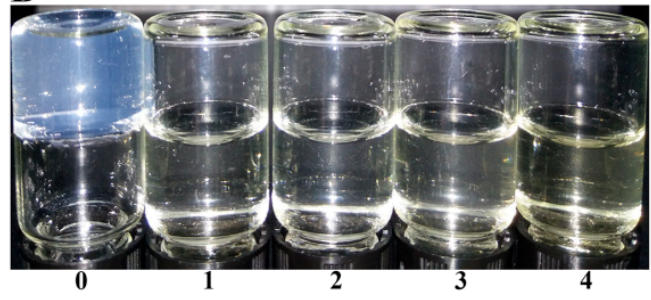

Figure 4. Gelation of pure gellan gum (PGG) and oxidized gellan gum (OGG) in different ionic conditions: (A) $\mathrm{Ca}^{2+}$, (B) $\mathrm{Na}^{+}$. The samples are (0) PGG, (1) OGG-1, (2) OGG-2, (3) OGG-3, (4) OGG-4.
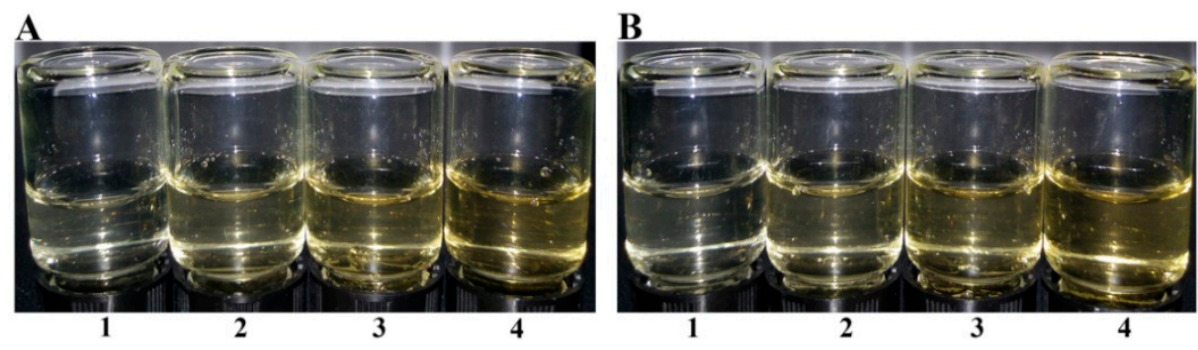

Figure 5. Gel conditions with different OGG-3 content: (A) $\mathrm{Ca}^{2+}$, (B) $\mathrm{Na}^{+}$. The contents are (1) $0.4 \%$, (2) $0.8 \%$, (3) $1.0 \%$, (4) $1.2 \%$.

Meanwhile, it was found that the oxidation of the gellan gum could significantly improve its cold water solubility, which could not be found in the gellan gum. Therefore, we assumed that the oxidation results were in more disorder in structure conformations and the loss of crystallinity, which made the OGGs easily dissolved in water but with poor gelling ability. However, Gong et al. [12] used $\mathrm{NaIO}_{4}$ to oxidatively cleave the low acyl gellan gum backbones which could still maintain its gelling 
ability. This difference may result from the different reaction reagent used and oxidation positions in the molecular structures.

\subsection{Antimicrobial Activities and Food Coating Applications}

\subsubsection{Antimicrobial Activities of the Oxidized Gellan Gums}

The MIC of the OGGs against E. coli and S. aureus were measured to evaluate the antimicrobial activities. Figure 6 shows the photographs of S. aureus and E. coli colonies grown in NB broths containing different contents of the OGGs. The values of MIC are shown in Table 2. The OGGs present a broad-spectrum antibacterial activity, which is improved with an increasing oxidation level. The OGG-4 presents the lowest MIC, which was similar to the values of oxidized schizophyllan [32]. It is proposed that the antibacterial activity of the OGGs is conferred by the new generated carboxyl groups. Abaev et al. [33] reported that the number of carboxylic groups attached to oxidized cellulosic materials was directly proportional to their antibacterial activity against S.aureus. Recently, Zi et al. [34] studied the effects of aldehyde and carboxyl groups on the antibacterial activity of oxidized amylose. They concluded that the antibacterial activity of dicarboxyl-amyloses was due to the acidic $\mathrm{pH}$ effect produced by the carboxyl groups [29].

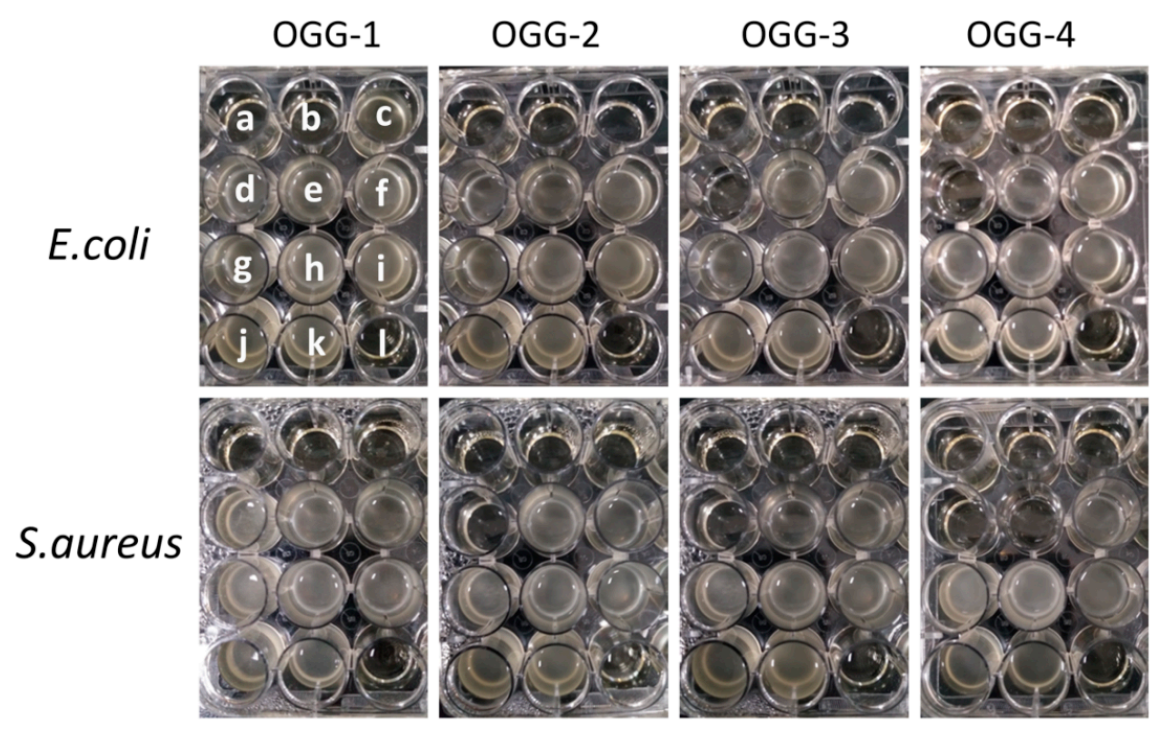

Figure 6. Photographs of bacterial colonies grown in NB (nutrient broth) containing different contents of oxidized gellan gum (OGG): (a) $80 \mathrm{mg} / \mathrm{mL}$, (b) $40 \mathrm{mg} / \mathrm{mL}$, (c) $20 \mathrm{mg} / \mathrm{mL}$, (d) $10 \mathrm{mg} / \mathrm{mL}$, (e) $5 \mathrm{mg} / \mathrm{mL}$, (f) $2.5 \mathrm{mg} / \mathrm{mL}$, (g) $1.25 \mathrm{mg} / \mathrm{mL}$, (h) $0.63 \mathrm{mg} / \mathrm{mL}$, (i) $0.32 \mathrm{mg} / \mathrm{mL}$, (j) $0.16 \mathrm{mg} / \mathrm{mL}$, (k) $0 \mathrm{mg} / \mathrm{mL}$, (l) NB medium.

Table 2. Minimum inhibitory concentration (MIC) of oxidized gellan gum with different oxidation levels on E. coli and S. aureus.

\begin{tabular}{ccc}
\hline Bacteria & Sample & MIC $(\mathbf{m g} / \mathbf{m L})$ \\
\hline E. coli & PGG & - \\
& OGG-1 & 40 \\
& OGG-2 & 20 \\
& OGG-3 & 20 \\
S. aureus & OGG-4 & 10 \\
& PGG & - \\
& OGG-1 & 20 \\
& OGG-2 & 20 \\
& OGG-3 & 10 \\
\hline
\end{tabular}


The antifungal activities of the OGGs were tested against $A$. niger colonies. The typical photographs of $A$. niger colonies grown on PDA plates are shown in Figure 7. The results showed that the growth of $A$. niger could be inhibited by a certain amount of the OGGs. At the same oxidation level (line in the figure), the number of $A$. niger colonies decreased steadily with an increasing concentration of the OGGs. Moreover, the higher the oxidation level at the same concentration (row in the figure), the less amount of $A$. niger colonies were found on the plate. Among them, the lowest number of $A$. niger colonies was in a concentration of $40 \mathrm{mg} / \mathrm{mL}$ of the OGG-4. These results showed that the OGGs had antifungal activity. Again, we propose that the antifungal activities of the OGGs are attributed to their carboxyl groups.

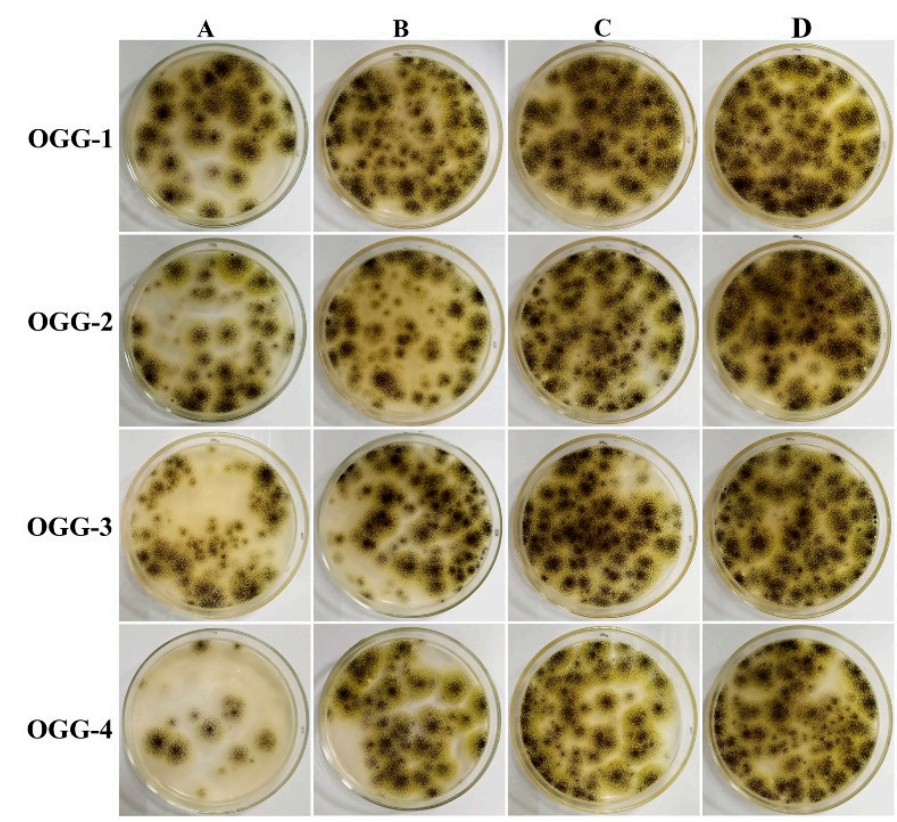

Figure 7. Typical photographs of A. niger colonies grown on potato dextrose agar plates: (A) $40 \mathrm{mg} / \mathrm{mL}$, (B) $20 \mathrm{mg} / \mathrm{mL}$, (C) $10 \mathrm{mg} / \mathrm{mL},(\mathbf{D}) 5 \mathrm{mg} / \mathrm{mL}$.

The results above showed that the OGGs could affect a relatively broad spectrum of microorganisms, although the inhibitory concentrations were large. It is known that a $\mathrm{pH}$ of 4.4-9.0 is the limiting range and more acidic conditions can be lethal to most organisms. The OGGs with sufficient carboxyl groups can increase the proton concentration thereby decreasing the environmental $\mathrm{pH}$ of microorganisms. This will alter the permeability and integrity of the microbial cell membranes, and also exert some disturbance in the nutrients transport, which causes the inactivation and death of microbes $[17,34,35]$. This antimicrobial action does not act in a mechanism-specific manner which will lead to antibiotic-resistant strains, as many antibiotics.

\subsubsection{Effect of the Oxidized Gellan Gums on Fruit Preservation as Antimicrobial Coatings}

The oxidized polysaccharides such as the OGGs prepared by green methods can be used as antimicrobial edible coatings for food preservation [18]. As an example, the OGGs were used as active coating materials in the preservation of apples [18]. Figure 8 shows the appearance of apples treated with different solutions of the OGG-4 after storage for a period of time. The decayed areas of the apples are shown on the right side of the figure. The $\mathrm{pH}$ was determined as 6.3, 3.3, and 3.1 for the control, $10 \mathrm{mg} / \mathrm{mL}$ OGG-4 solution, and $20 \mathrm{mg} / \mathrm{mL}$ OGG-4 solution, respectively. It can be seen that control one began to decay in 5 days. When the solution contained OGGs, the apple began to decay in 10 days. As the concentration of the OGGs increased, the rate of rot became slower. The results clearly showed that solutions containing the OGGs could effectively extend apple storage time due to their 
antibacterial and antifungal activities [18]. Therefore, the OGGs have potential applications as coating materials for food preservation.
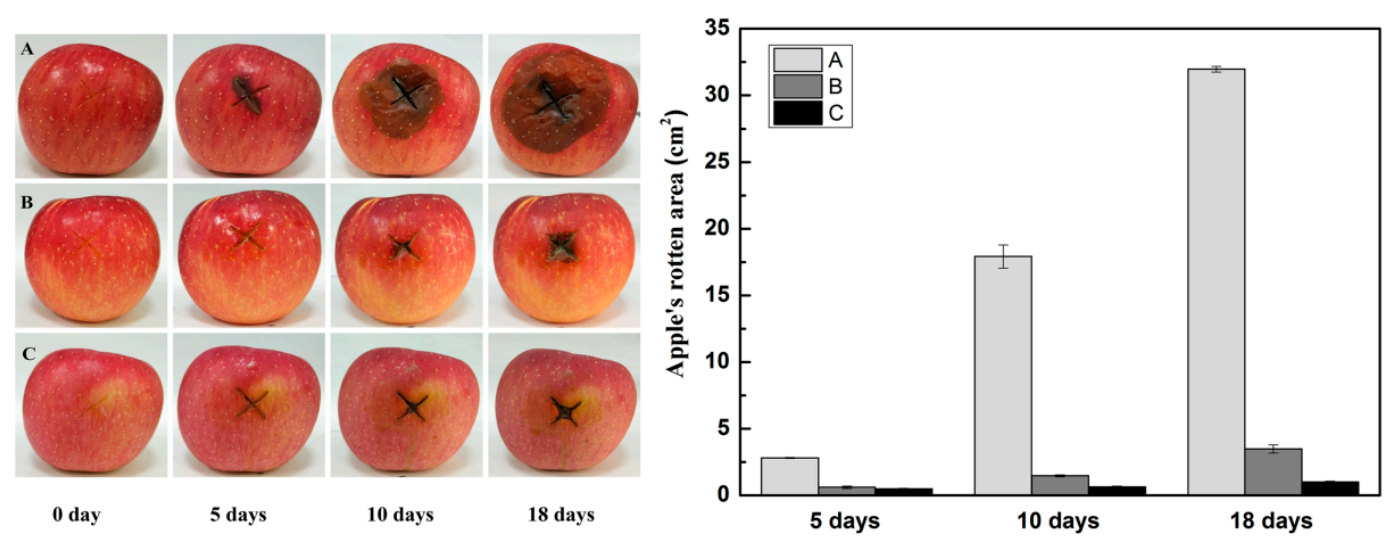

Figure 8. The appearance of apples after treatment by different solutions for different days: (A) $0 \mathrm{mg} / \mathrm{mL}$ OGG-4 solution; (B) $10 \mathrm{mg} / \mathrm{mL}$ OGG-4 solution; (C) $20 \mathrm{mg} / \mathrm{mL}$ OGG-4 solution.

\section{Conclusions}

The oxidized gellan gums with different oxidation levels were successfully prepared by hydrogen peroxide and the copper sulfate redox system. The infrared spectrum and ${ }^{1} \mathrm{H}-\mathrm{NMR}$ spectroscopy analysis demonstrated that the carboxyl group had been successfully introduced into the gum structure. The oxidation mechanisms were discussed and the cleavage of glycoside bonds might occur. The OGGs lost the abilities of gelation even in the presence of ions. Oxidation gives the OGGs a broad-spectrum antimicrobial activity against bacterials (Escherichia coli and Staphylococcus aureus) and fungus (A. niger), and the activity increases with an increase in the oxidation level. The OGGs are applied as coating materials and can extend the storage time of apples. The study shows that new gellan gum derivatives by Fenton type oxidation have potential applications as antimicrobial coating materials in the food industry.

Author Contributions: X.Z. and S.F. conceived and designed the experiments; Y.L. performed the synthesis experiments; X.Z. and Y.L. performed the chemical analysis; Y.L. and X.Z. analyzed the data; Y.L. and S.F. drafted the manuscript; Y.L. revised the manuscript; S.F. was responsible for raising the funds.

Funding: This research was funded by the Zhejiang Provincial Collaborative Innovation Center of Food Safety and Nutrition, grant number 2017SICR116.

Conflicts of Interest: The authors declare that they have no conflict of interest.

\section{References}

1. Hilal, Y.; Neva, K. Microbial exopolysaccharides: Resources and bioactive properties. Process Biochem. 2018, $72,41-46$.

2. Oikonomou, E.K.; Christov, N.; Cristobal, G.; Bourgaux, C.; Heux, L.; Boucenna, I.; Berret, J.F. Design of eco-friendly fabric softeners: Structure, rheology and interaction with cellulose nanocrystals. J. Colloid Interface Sci. 2018, 525, 206-215. [CrossRef] [PubMed]

3. Liu, J; Wang, X.; Pu, H.; Liu, S.; Kan, J.; Jin, C. Recent advances in endophytic exopolysaccharides: Production, structural characterization, physiological role and biological activity. Carbohydr. Polym. 2016, 157, 1113-1124. [CrossRef] [PubMed]

4. Hu, Z.H.; Omer, A.M.; Ouyang, X.; Yu, D. Fabrication of carboxylated cellulose nanocrystal/sodium alginate hydrogel beads for adsorption of pb(ii) from aqueous solution. Int. J. Biol. Macromol. 2018, 108, 149-157. [CrossRef] [PubMed]

5. Karaki, N.; Aljawish, A.; Humeau, C.; Muniglia, L.; Jasniewski, J. Enzymatic modification of polysaccharides: Mechanisms, properties, and potential applications: A review. Enzyme Microb. Technol. 2016, 90, 1-18. [CrossRef] [PubMed] 
6. Morris, E.R.; Nishinari, K.; Rinaudo, M. Gelation of gellan-A review. Food Hydrocoll. 2012, $28,373-411$. [CrossRef]

7. Zia, K.M.; Tabasum, S.; Khan, M.F.; Akram, N.; Akhter, N.; Noreen, A.; Zuber, M. Recent trends on gellan gum blends with natural and synthetic polymers: A review. Int. J. Biol. Macromol. 2018, 109, 1068-1087. [CrossRef]

8. Bacelar, A.H.; Silva-Correia, J.; Oliveira, J.M.; Reis, R.L. Recent progress in gellan gum hydrogels provided by functionalization strategies. J. Mater. Chem. B 2016, 4, 6164-6174. [CrossRef]

9. Ahuja, M.; Singh, S.; Kumar, A. Evaluation of carboxymethyl gellan gum as a mucoadhesive polymer. Int. J. Biol. Macromol. 2013, 53, 114-121. [CrossRef]

10. Matricardi, P.; Cencetti, C.; Ria, R.; Alhaique, F.; Coviello, T. Preparation and characterization of novel gellan gum hydrogels suitable for modified drug release. Molecules 2009, 14, 3376-3391. [CrossRef]

11. Redouan, E.; Emmanuel, P.; Christine, B.; Bernard, C.; Josiane, C.; Cédric, D. Development of new ulvan-like polymer by regioselective oxidation of gellan exopolysaccharide using TEMPO reagent. Carbohydr. Polym. 2010, 80, 485-490. [CrossRef]

12. Gong, Y.; Wang, C.; Lai, R.C.; Su, K.; Zhang, F.; Wang, D.A. An improved injectable polysaccharide hydrogel: Modified gellan gum for long-term cartilage regeneration in vitro. J. Mater. Chem. 2009, 19, 1968-1977. [CrossRef]

13. Tang, Y.; Sun, J.; Fan, H.; Zhang, X. An improved complex gel of modified gellan gum and carboxymethyl chitosan for chondrocytes encapsulation. Carbohydr. Polym. 2012, 88, 46-53. [CrossRef]

14. Kristiansen, K.A.; Potthast, A.; Christensen, B.E. Periodate oxidation of polysaccharides for modification of chemical and physical properties. Carbohydr. Res. 2010, 345, 1264-1271. [CrossRef] [PubMed]

15. Duan, J.; Kasper, D.L. Oxidative depolymerization of polysaccharides by reactive oxygen/nitrogen species. Glycobiology 2011, 21, 401-409. [CrossRef] [PubMed]

16. Ying, Z.; Ye, Y.X.; Zhang, W.W.; Li, S.L.; Chen, J.; Wang, S.T.; Li, D.F.; Mu, C.D. Oxidized amylose with high carboxyl content: A promising solubilizer and carrier of linalool for antimicrobial activity. Carbohydr. Polym. 2016, 154, 13-19.

17. Zhu, M.J.; Ge, L.M.; Lyu, Y.; Zi, Y.X.; Li, X.Y.; Li, D.F.; Mu, C.D. Preparation, characterization and antibacterial activity of oxidized K-carrageenan. Carbohydr. Polym. 2017, 174, 1051-1058. [CrossRef]

18. Ye, Y.; Ren, H.; Zhu, S.; Tan, H.; Li, X.; Li, D.; Mu, C. Synthesis of oxidized $\beta$-cyclodextrin with high aqueous solubility and broad-spectrum antimicrobial activity. Carbohydr. Polym. 2017, 177, 97-104. [CrossRef]

19. Moura, F.A.D.; Pereira, J.M.; Silva, D.O.D.; Zavareze, E.D.R.; Moreira, A.D.S.; Helbig, E.; Dias, A.R.G. Effects of oxidative treatment on the physicochemical, rheological and functional properties of oat $\beta$-glucan. Food Chem. 2011, 128, 982-987. [CrossRef]

20. Liu, L.; Wen, H.; Rao, Z.; Zhu, C.; Liu, M.; Min, L.; Fan, L.; Tao, S. Preparation and Characterization of Chitosan-Collagen Peptide/Oxidized Konjac Glucomannan Hydrogel. Int. J. Biol. Macromol. 2018, 108, 376-382. [CrossRef]

21. Rosík, J.; Kardošová, A.; Kubala, J. Infrared spectroscopy of peach-gum polysaccharides of Prunus persica (L.) Batsch. Carbohydr. Res. 1971, 18, 151-156. [CrossRef]

22. Zhang, Y.R.; Wang, X.L.; Zhao, G.M.; Wang, Y.Z. Preparation and properties of oxidized starch with high degree of oxidation. Carbohydr. Polym. 2012, 87, 2554-2562. [CrossRef]

23. Liang, X.; Du, L.; Su, F.; Parekh, H.S.; Su, W. The application of quantitative NMR for the facile, rapid and reliable determination of clindamycin phosphate in a conventional tablet formulation. Magn. Reson. Chem. 2014, 52, 178-182. [CrossRef] [PubMed]

24. Coutinho, D.F.; Sant, S.V.; Shin, H.; Oliveira, J.T.; Gomes, M.E.; Neves, N.M.; Khademhosseini, A.; Reis, R.L. Modified gellan gum hydrogels with tunable physical and mechanical properties. Biomaterials 2010, 31, 7494-7502. [CrossRef] [PubMed]

25. Lyu, Y.; Ren, H.; Yu, M.C.; Li, X.Y.; Li, D.F.; Mu, C.D. Using oxidized amylose as carrier of linalool for the development of antibacterial wound dressing. Carbohydr. Polym. 2017, 174, 1095-1105. [CrossRef] [PubMed]

26. Vanier, N.L.; El Halal, S.L.; Dias, A.R.; Dias, R.Z.E.; Zavareze, E.D.R. Molecular structure, functionality and applications of oxidized starches: A review. Food Chem. 2017, 221, 1546-1559. [CrossRef] [PubMed]

27. Liang, X.; Li, N.; Chen, X.; Su, W. Asymmetric a-oxyamination of aldehydes by synergistic catalysis of imidazolethiones and metal salts. RSC Adv. 2014, 4, 44039-44042. [CrossRef] 
28. Sangseethong, K.; Termvejsayanon, N.; Sriroth, K. Characterization of physicochemical properties of hypochlorite- and peroxide-oxidized cassava starches. Carbohydr. Polym. 2010, 82, 446-453. [CrossRef]

29. Bissaro, B.; Røhr, Å.K.; Müller, G.; Chylenski, P.; Skaugen, M.; Forsberg, Z.; Horn, S.J.; Vaaje-Kolstad, G.; Eijsink, V.G.H. Oxidative cleavage of polysaccharides by monocopper enzymes depends on $\mathrm{H}_{2} \mathrm{O}_{2}$. Nat. Chem. Biol. 2017, 13, 1123-1128. [CrossRef]

30. Chandrasekaran, R.; Radha, A. Molecular architectures and functional properties of gellan gum and related polysaccharides. Trends Food Sci. Technol. 1995, 6, 143-148. [CrossRef]

31. Upstill, C.; Atkins, E.D.T.; Attwool, P.T. Helical conformations of gellan gum. Int. J. Biol. Macromol. 1986, 8 , 275-288. [CrossRef]

32. Jayakumar, G.C.; Kanth, S.V.; Chandrasekaran, B.; Rao, J.R.; Nair, B.U. Preparation and antimicrobial activity of scleraldehyde from schizophyllum commune. Carbohydr. Res. 2010, 345, 2213-2219. [CrossRef]

33. Abaev, Y.; Kaputsky, V.; Adarchenko, A.A.; Sobeshchuk, O.P. Mechanism of antibacterial effects of monocarboxyl cellulose and other ion exchange derivatives of cellulose. Antibiot. Med. Biotekhnol. 1986, 31, 624-628. [PubMed]

34. Zi, Y.X.; Zhu, M.J.; Li, X.Y.; Xu, Y.B.; Wei, H.; Li, D.F.; Mu, C.D. Effects of carboxyl and aldehyde groups on the antibacterial activity of oxidized amylose. Carbohydr. Polym. 2018, 192, 118-125. [CrossRef] [PubMed]

35. Spangler, D.; Rothenburger, S.; Nguyen, K.; Jampani, H.; Weiss, S.; Bhende, S. In vitro antimicrobial activity of oxidized regenerated cellulose against antibiotic-resistant microorganisms. Surg. Infect. 2003, 4, 255-262. [CrossRef] [PubMed]

(C) 2019 by the authors. Licensee MDPI, Basel, Switzerland. This article is an open access article distributed under the terms and conditions of the Creative Commons Attribution (CC BY) license (http:/ / creativecommons.org/licenses/by/4.0/). 